\title{
Anaphylaxis after accidental ingestion of kiwi fruit
}

\author{
Ewa Gawrońska-Ukleja, Anna Różalska, Natalia Ukleja-Sokołowska, Magdalena Żbikowska-Gotz, Zbigniew Bartuzi
}

Department and Clinic of Allergy, Clinical Immunology and Internal Diseases, Nicolaus Copernicus University, Collegium Medicum, Bydgoszcz, Poland

Head: Prof. Zbigniew Bartuzi MD, PhD

Postep Derm Alergol 2013; XXX, 3: 192-194

DOI: 10.5114/pdia.2013.35623

\begin{abstract}
Numerous cases of anaphylaxis after ingestion of kiwi fruit, after the skin tests and during oral immunotherapy were described. The article describes the case of severe anaphylactic reaction that occurred in a 55-year-old patient after accidental ingestion of kiwi. Allergy to kiwi fruit was confirmed by a native test with fresh kiwi fruit. After the test, the patient experienced generalized organ response in the form of headache, general weakness and rashes on the neck and breast, and dyspnea. The patient had significantly elevated levels of total IgE and IgE specific to kiwi fruit.
\end{abstract}

Key words: allergy, anaphylaxis, kiwi fruit.

\section{Introduction}

The first description of allergy to kiwi fruit comes from 1981 and it relates to a 53-year-old woman who has experienced acute urticaria, wheezing and swelling of the lar$y n x$ [1]. Nowadays kiwi allergy is becoming increasingly important and is particularly prevalent in young children. At the moment, according to reports from 2011, there are no accurate epidemiological data on allergic reactions to this tasty fruit [2]. Kiwi allergen is a protein. Its molecular weight is approximately $30 \mathrm{kDa}$, and the concentration of the major allergen of this fruit depends on the variety [3].

Clinical symptoms after eating kiwi are mostly lgE-dependent reactions, mainly occurring around the mouth (oral allergy syndrome - OAS) [4, 5]. There may also appear changes in the skin such as acute urticaria, contact urticaria, atopic dermatitis and contact dermatitis [6-9]. Symptoms of asthma were found in 3-4\% of patients allergic to kiwi protein, the frequency is the same for gastrointestinal symptoms [10]. The most dangerous, life-threatening allergic reaction to food is an anaphylactic shock.

In the medical literature, there are numerous descriptions of cases of anaphylaxis after eating kiwi fruit, but also after skin tests and during oral immunotherapy [11-13]. In 1992, an interesting case was described of a 29-year-old woman with several episodes of severe anaphylaxis after eating kiwi fruit, including three full-blown anaphylactic shocks. The first two shocks occurred immediately after eating fresh fruits and the third episode occurred as a total loss of consciousness caused by a small amount of kiwi left on the knife, which was used to prepare a strawberry dessert served to the patient in a restaurant [11]. Since the clinical symptoms reported after ingestion of kiwi are serious and may lead to the loss of consciousness, in some cases (idiopathic anaphylaxis) it is possible to consider kiwi as a hidden allergen.

Numerous reports indicate cross-reactions with kiwi allergens and plant and food allergens. Kiwi gives crossreactions with Japanese cedar [14], meadow fescue [15], olive [16], wheat [17], latex [18, 19], melon, sesame seeds, poppy seeds, hazelnuts, potatoes, peach papaya, pineapple and apple [20-24], pepper [25] and tomato [26].

In the diagnosis of allergy to kiwi, native skin prick-byprick tests with skin and pulp of the fruit have the advantage over skin prick tests with standardized allergens [18]. Still the gold standard in the diagnosis of food allergy is a double-blind, placebo-controlled food challenge DBPCFC [27]. The patient can also perform the labial food challenge - LFC [28] and assess the concentration of specific IgE against kiwi allergen.

\section{Case report}

Patient, 55 years old, male, was admitted to the Department and Clinic of Allergy, Clinical Immunology and Internal Diseases to perform an allergy diagnostic procedure.

In May 2010, after an accidental ingestion of kiwi hidden in vanilla ice cream (it is most likely that a small amount

Address for correspondence: Ewa Gawrońska-Ukleja MD, PhD, Department and Clinic of Allergy, Clinical Immunology and Internal Diseases, Collegium Medicum, University Hospital No. 2, 75 Ujejskiego St, 85-168 Bydgoszcz, Poland, phone: +48 523655416 , e-mail: kikalerg@cm.umk.pl Received: 24.09.2012, accepted: 29.04.2013. 
of kiwi fruit was on a spoon used for scooping ice cream) the patient developed shortness of breath, swelling and numbness of tongue, hot flashes, dizziness and temporary loss of consciousness, involuntary urination and defecation. Symptoms subsided after taking 2 tablets of the antihistamine drug - cetirizine and a tablet of calcium. During the interview, it was revealed that several years before, after eating kiwi the patient developed numbness of lips and tongue, and generalized skin rash. The patient eliminated kiwi from his diet. Up to the hospitalization he was not diagnosed in the direction of kiwi hypersensitivity. Three weeks before being admitted to the hospital the patient experienced malaise, a feeling of scratching in the throat and flushing of cheeks after eating raw garlic. Previously, garlic was well tolerated.

The patient also noticed that during contact with construction dust he experienced hot and itchy skin, especially on the face. The other reported symptoms were dyspnea and a tiring, dry cough with increasing intensity for the last 3 weeks. Physical examination on admission does not deviate from normal.

We performed skin prick tests (SPT) with food allergens using a set from Allergopharma (allergens included hen's egg, cow's milk, cocoa, tomatoes, carp, apples, bananas, strawberries, rye flour, wheat flour, peanuts, nuts, celery, pork, poultry, citrus), which were negative. The skin prick test using a standardized kiwi allergen was not performed since the allergen extract was not available. Eventually, we performed a prick-by-prick test with fresh kiwi fruit.

The result of the prick-by-prick test was strongly positive (histamine $4 \mathrm{~mm} / 4 \mathrm{~mm}$, negative control - negative, kiwi $9 \mathrm{~mm} / 12 \mathrm{~mm}$ ). Ten minutes after the test, the patient experienced severe headache, weakness, rash on the neck and décolleté, and shortness of breath. Symptoms disappeared after administration of $4 \mathrm{mg}$ of dexamethasone i.v. and 1 tablet of the antihistamine drug (cetirizine). The patient also had several immunological tests using enzymatic Hycor Biomedical Technic EIA (WHO standard results are shown in $\mathrm{kU} / \mathrm{l})$. The patient's level of specific IgE against kiwi was $2.75 \mathrm{IU} / \mathrm{ml}$ (class II). Specific lgE concentration was not elevated to birch, grass pollen, trees, mugwort, house dust mites, molds, mix. spices, banana and latex. It should be noted that during the test we used a mix of spices, which included garlic, i.e. the spice causing symptoms according to the patient's interview. Total lgE concentration was $176.42 \mathrm{IU} / \mathrm{ml}$ (total lgE level is considered elevated when above $100 \mathrm{kU} / \mathrm{l}$ ).

The patient had eosinophilia in $1 \mathrm{~mm}^{3}$ of normal peripheral blood (340 cells). The patient had a detailed diagnosis using the immunoblotting method. In this method, no positive signal was obtained. In addition, because the patient reported dyspnea of paroxysmal character, spirometry was performed with the histamine provocation test. The patient demonstrated typical asthmatic bronchial hyperreactivity ( $\mathrm{FEV}_{1}$ decreased $24.76 \%$ ).

The patient's diagnosis was established as allergy to kiwi and controlled asthma. The patient was discharged home with instructions to continue treatment under the supervision of the Allergy Clinic, total elimination of kiwi fruit from his diet (both in the fresh and processed form) and avoidance of cross-reaction to kiwi allergens (birch, wheat, latex, melon, sesame seeds, poppy seeds, nuts, potatoes, peach, papaya, pineapple, apple, red pepper and tomato). We recommended the need for a so-called "rescue set" (adrenaline in auto syringes, oral steroids, antihistamines) and inhaled steroids to control asthma.

\section{Discussion}

The described case shows the great allergenic strength of kiwi. A small amount of the allergen left on an ice cream scooping spoon can result in a full-blown life-threatening anaphylactic shock. As in the case described in the literature, when a 29-year-old woman had an anaphylactic shock caused by a small amount of kiwi left on the knife, which was used for the preparation of a strawberry dessert in a restaurant [11].

The severity of allergy in our patient is described by the fact that he suffered anaphylaxis 10 min after the prickby-prick test with fresh kiwi fruit. The present case shows that native tests should be performed by an experienced medical doctor, because the available literature also describes the reaction of the system in a 50-year-old man after a skin test [18].

Strongly positive prick-by-prick skin tests with fresh kiwi fruit and symptoms that occurred after the test have confirmed the source of anaphylactic reaction in our patient. According to the data in the literature, tests using fresh food have high specificity [29]. The gold standard in the diagnosis of food allergy is DBPCFC. In the case of kiwi allergy, diagnostic efficacy has been demonstrated in 66-68\% of patients [27]. In the described patient, we decided against DBPCFC due to organ reaction observed after the prick-byprick test, which clearly confirmed the allergy. Kiwi allergy in our patient was confirmed by evaluating the level of specific IgE to kiwi (class II). Although there was no signal in immunoblotting, we presume that it did not exclude the presence of specific antibodies against kiwi protein extract and the results may be a consequence of their low concentrations in the blood serum tested and partial change in allergen particles due to protein denaturation.

In patient's diagnosis we failed to demonstrate hyperreactivity to allergens that cross-react with kiwi. It was recommended, however, to avoid allergens that may provide potential cross-reaction with fresh kiwi fruit.

Food allergy, including allergy to kiwi, significantly affects the quality of life. Patients with food allergies are afraid of accidental exposure to an allergen. Patients with allergy to kiwi should strictly eliminate this fruit from their diet and also all the fruits potentially providing cross-reactions. Patients need to carefully read labels of consumed articles. Every patient should have a rescue medication (epinephrine in auto-syringe, antihistamine, steroids). Our patient 
was equipped with this medication. High hopes are associated with specific immunotherapy [30], but the efficacy of immunotherapy is currently difficult to be determined due to the standardization of food used for desensitization therapy. This treatment is still used in small groups of patients [31].

Future in the diagnosis of allergy to kiwi is related with skin testing of recombinant allergens obtained by genetic engineering. The use of recombinant allergens will enable the identification of specific allergen proteins recognized by specific anti-kiwi IgE (recognized by SPT or allergen provocation tests) [32]. Unfortunately, this method is currently unavailable [33].

\section{References}

1. Fine AJ. Hypersensitivity reaction to kiwi fruit (Chinese gooseberry, Actinidia chinensis). J Allergy Clin Immunol 1981; 68: 235-7.

2. Le TM, Fritsche P, Bublin M, et al. Differences in the allergenicity of 6 different kiwifruit cultivars analyzed by prickto-prick testing, open food challenges, and ELISA. J Allergy Clin Immunol 2011; 127: 677-9.

3. Oberhuber C, Bulley SM, Ballmer-Weber BK, et al. Characterization of Bet $v$ 1-related allergens from kiwifruit relevant for patients with combined kiwifruit and birch pollen allergy. Mol Nutr Food Res 2008; 52 Suppl 2: S230-40.

4. Mancuso G, Berdondini RM. Oral allergy syndrome from kiwi fruit after a lover's kiss. Contact Dermatitis 2001; 45: 41.

5. Dutau GRF. Le syndrome des allergies induites par le baiser/Kiss-induced allergy. Revue francaise d allergologie 2006; 46: 80-4.

6. Veraldi S, Schianchi-Veraldi R. Contact urticaria from kiwi fruit. Contact Dermatitis 1990; 22: 244.

7. Rademaker M. Allergic contact dermatitis from kiwi fruit vine (actinidia chinensis). Contact Dermatitis 1996; 34: 221-2.

8. Zina AM, Bundino S. Contact urticaria to actinidia chinensis. Contact Dermatitis 1983; 9: 85.

9. Huertas AJ, Iriarte P, Mengual P. Sensitization to kiwi skin. Med Clin (Barc) 1998; 111: 518-9.

10. Rance F, Dutau G. Asthma and food allergy: report of 163 pediatric cases. Arch Pediatr 2002; 9 Suppl 3: 402s-7s.

11. Joral AGJ. Food allergy due to sensitivity to Kiwi (Abstract). Allergy 1992; 47 (suppl).

12. Mempel M, Rakoski J, Ring J, Ollert M. Severe anaphylaxis to kiwi fruit: immunologic changes related to successful sublingual allergen immunotherapy. J Allergy Clin Immunol 2003; 111: 1406-9.

13. Shimizu T, Morikawa A. Anaphylaxis to kiwi fruit in a 12 -yearold boy. J Asthma 1995; 32: 159-60.

14. Ishida T, Murai K, Yasuda T, et al. Oral allergy syndrome in patients with Japanese cedar pollinosis. Nippon Jibiinkoka Gakkai Kaiho 2000; 103: 199-205.

15. Gavrovic-Jankulovic M, Cirkovic T, Burazer L, et al. IgE crossreactivity between meadow fescue pollen and kiwi fruit in patients' sera with sensitivity to both extracts. I Investig Allergol Clin Immunol 2002; 12: 279-86.

16. Florido Lopez JF, Quiralte EJ, Arias de Saavedra Alias JM, et al. An allergen from Olea europaea pollen (Ole e 7 ) is associated with plant-derived food anaphylaxis. Allergy 2002; 57 Suppl 71: 53-9.
17. Eriksson NE, Moller C, Werner S, et al. Self-reported food hypersensitivity in Sweden, Denmark, Estonia, Lithuania, and Russia. J Investig Allergol Clin Immunol 2004; 14: 70-9.

18. Novembre E, Bernardini R, Bertini G, et al. Skin-prick-testinduced anaphylaxis. Allergy 1995; 50: 511-3.

19. Sanchez-Monge R, Blanco C, Perales AD, et al. Class I chitinases, the panallergens responsible for the latex-fruit syndrome, are induced by ethylene treatment and inactivated by heating. I Allergy Clin Immunol 2000; 106: 190-5.

20. Rodriguez J, Crespo JF, Burks W, et al. Randomized, doubleblind, crossover challenge study in 53 subjects reporting adverse reactions to melon (Cucumis melo). J Allergy Clin Immunol 2000; 106: 968-72.

21. Diaz-Perales A, Collada C, Blanco C, et al. Cross-reactions in the latex-fruit syndrome: a relevant role of chitinases but not of complex asparagine-linked glycans. J Allergy Clin Immunol 1999; 104: 681-7.

22. Moller M, Kayma M, Vieluf D, et al. Determination and characterization of cross-reacting allergens in latex, avocado, banana, and kiwi fruit. Allergy 1998; 53: 289-96.

23. Gall H, Kalveram K, Forck G, Tummers U. Crossreactivity between kiwi fruit and thiol proteinases, pollen and foodstuffs. Allergologie 1990; 13: 447-51.

24. Barral P, Batanero E, Palomares O, et al. A major allergen from pollen defines a novel family of plant proteins and shows intra- and interspecies [correction of interspecie] cross-reactivity. J Immunol 2004; 172: 3644-51.

25. Breiteneder $\mathrm{H}$. Thaumatin-like proteins: a new family of pollen and fruit allergens. Allergy 2004; 59: 479-81.

26. Gawrońska-Ukleja E, Ukleja N, Sokołowski L, Bartuzi Z. Diagnostic value of prick by prick test with fresh fruits and vegetables in diagnosis of food allergy. Alergologia Info 2009; 2: 65-9.

27. Rosińska-Więckowicz A, Czarnecka-Operacz M. Skin tests with native alimentary allergens in the diagnostics of food allergy. Postep Derm Alergol 2009; 26: 270-9.

28. Ranee F, Dutau G. Labial food challenge in children with food allergy. Pediatr Allergy Immunol 1997; 8: 41-4.

29. Castillo R, Delgado J, Quiralte J, et al. Food hypersensitivity among adult patients: epidemiological and clinical aspects. Allergol Immunopathol (Madr) 1996; 24: 93-7.

30. Vickery BP, Burks W. Oral immunotherapy for food allergy. Curr Opin Pediatr 2010; 22: 765-70.

31. Kerzl R, Simonowa A, Ring J, et al. Life-threatening anaphylaxis to kiwi fruit: protective sublingual allergen immunotherapy effect persists even after discontinuation. J Allergy Clin Immunol 2007; 119: 507-8.

32. Jutel M. Alergeny rekombinowane, przełom $w$ diagnostyce i terapii chorób alergicznych. Alergologia Współczesna 2004; 1: 2-8.

33. Ferreira FD, Mayer P, Sperr WR, et al. Induction of IgE antibodies with predefined specificity in rhesus monkeys with recombinant birch pollen allergens, Bet $v 1$ and Bet v 2 . J Allergy Clin Immunol 1996; 97: 95-103. 